\title{
Dysregulation of RGS Proteins by Psychostimulants
}

\begin{abstract}
Keywords: RGS Proteins; Dopamine; Dopamine D2 Receptors; Psychostimulant

\section{Abstract}

Regulator of $G$ protein signaling (RGS) proteins are a class of proteins that negatively modulate GPCR-mediated G protein signaling. The distribution of subtypes of RGS proteins is brain region specific. Several subtypes of RGS proteins are present in the mesolimbic dopaminergic pathway and are subjected to modulation by psychostimulants. Acute or chronic exposure to psychostimulants induces changes in mRNA levels of RGS in a subtype-, brain region-, and time-dependent manner. The dynamic changes in the abundance of RGS proteins by psychostimulant treatment may be associated with dopamine receptor sensitization or desensitization, a potential mechanism underlying drug sensitization or tolerance. Small molecule RGS inhibitors are useful tools for studying in vivo function of RGS proteins and are potential therapeutics for the treatment of psychostimulant addiction.
\end{abstract}

\section{Abbreviations \\ AMPH: Amphetamine; RGS Proteins: Regulator of G Protein Signaling Proteins; VTA: Ventral Tegmental Area; NAC: Nucleus Accumbens; DAT: Dopamine Transporter; cAMP: Cyclic Adenosine Monophosphate; NMDA Receptor: N-Methyl-D-Aspartate Receptor; GIRK: G-Protein-Coupled Inwardly Rectifying Potassium Channel; $\mathrm{GABA}_{\mathrm{B}}$ Receptor: $\Gamma$-Aminobutyric Acid Type B Receptor; MGlur5: Glutamate Receptor5}

\section{Introduction}

Addiction to psychostimulant drugs is a chronic and devastating disease. According to National Survey on Drug Use and Health in 2012, there were approximately 1.4 million current cocaine users and 12 million lifetime methamphetamine (METH) users in the United States [1]. The estimated economic cost to society due to the use of illicit drugs including psychostimulants was more than $\$ 193$ billion in 2007. However, there are still no effective medications to date that are available for treatment of psychostimulant addiction. Thus, there is an urgency to identify novel targets that are involved in psychostimulant-induced neuroplasticity in order to develop new and effective pharmacotherapies for psychostimulant addiction.

Psychostimulants activate the mesolimbic dopamine reward system, which consists of dopaminergic neurons originating from the ventral tegmental area (VTA) and projecting to forebrain regions such as the nucleus accumbens (NAc), prefrontal cortex, amygdala, and hippocampus. The addictive property of psychostimulants such as cocaine and amphetamine (AMPH) is their ability to increase dopamine in the synapse primarily through interaction with dopamine transporter (DAT), a major site of action for psychostimulants. Cocaine, a DAT blocker, exerts its action by increasing synaptic dopamine levels through blockade of dopamine reuptake. In contrast, AMPH, a DAT substrate, is able to bind to DAT and translocate intracellularly, thereby reversing the transport of intracellular dopamine to increase the extracellular dopamine levels.

\section{Journal of Addiction \& Prevention}

Rong Chen* and Scott E. Hemby

Department of Physiology \& Pharmacology, Wake Forest University School of Medicine, Winston Salem, NC 27157, USA

\section{*Address for Correspondence}

Dr. Rong Chen Ph.D., Department of Physiology \& Pharmacology, Wake Forest University School of Medicine, Winston Salem, NC 27157, USA, Tel: 336-716-8605; Fax: 336-713-1545; E-mail: rchen@wakehealth.edu

Submission: 23 December, 2013

Accepted: 02 April, 2014

Published: 04 April, 2014

Copyright: () 2014 Chen R, et al. This is an open access article distributed under the Creative Commons Attribution License, which permits unrestricted use, distribution, and reproduction in any medium, provided the original work is properly cited.

Prolonged and repeated dopamine surges in the synapse produced by psychostimulants lead to stimulation of dopamine receptors and cause profound neuroadaptations in gene transcription, protein translation and synaptic activity, which underlie drug-associated learning and memory. A pronounced and persistent neurochemical phenotype resulting from chronic cocaine exposure is the reduced dopamine D2 receptor in the striatal density due to overstimulation, which has been reported in drug addicts [2], non-human primates [3], and rodents $[4,5]$. The reduced striatal D2 receptor availability has been associated with propensity for drug-taking behavior [6-8]. Additionally, midbrain dopamine D2 receptors (autoreceptors) are inversely correlated with impulsivity and AMPH craving in humans [9]. Therefore, a major pharmacological therapy for psychostimulant addiction has emphasized the normalization of dopamine transmission by overcoming deficits in dopamine D2 receptor function. Dopamine D2 receptors are modulated by a network of proteins such as protein kinases, signaling molecules, and trafficking proteins [10]; however it has become apparent in recent years that regulator of $\mathrm{G}$ protein signaling (RGS) proteins can also regulate the trafficking and activity of D2 receptors [11,12]. Because the expression of RGS proteins is sensitive to psychostimulant treatments (see review in [13]), RGS proteins may play an important role in regulation of dopamine transmission, thus contributing to the addiction process.

\section{Dopamine Receptors in Drug Addiction}

Dopamine released by psychostimulants activates dopamine receptors that are located at the somatodendritic, presynaptic and postsynaptic compartments of neurons throughout the mesolimbic dopamine pathway. There are 5 subtypes of dopamine receptors in the brain. D1-like receptors, consisting of D1 and D5 subtypes, are coupled to Gas protein to stimulate adenylyl cyclase activity and thereby increase cellular cyclic adenosine monophosphate (cAMP) levels. In contrast, D2-like receptors, consisting of D2, D3 and D4 subtypes, are coupled to Gai/o proteins to inhibit adenylyl cyclase and thus decrease cAMP levels. Dopamine receptors are integral components of the mesolimbic dopamine pathway and have long been implicated in drug-seeking and taking behavior. Studies using receptor agonists and mice with a deletion of dopamine receptor subtype reveal specific roles of each subtype in drug-taking and seeking behavior (see review in [14]). For example, blockade of D1 or D2 receptors in the NAc decreases cocaine self-administration [1517]. Agonists of D2 receptors, but not D1 receptors, reinstate cocaine- 
seeking behavior [18]. Although major efforts have been devoted in the past to evaluate the efficacies of novel ligands selective for dopamine receptors, especially for $\mathrm{D} 2$ receptors, to treat drug addicts, none have been shown to be effective to date [19,20]. In recent years, focus has been shifted to compounds that are indirect D2 receptor agonists or D2 receptor modulators. Recent clinical trials with indirect dopamine receptor agonists such as AMPH derivatives are promising [see review in [21]. Therefore, it is imperative to understand the regulatory machineries underlying receptor adaptations to psychostimulant exposure, which will provide opportunities for identifying novel drug targets.

\section{RGS Proteins: Function and Brain Expression}

RGS proteins are a class of proteins that negatively modulate the function of heterotrimeric $G$ proteins. $G$ proteins are composed of single $\alpha, \beta, \gamma$ subunits which form two functional subunits, $G \alpha$ and $\mathrm{G} \beta \gamma$. Activation of G protein-coupled receptors (GPCRs) promotes the exchanges of GTP for GDP on the Ga subunit and dissociation of $G \beta \gamma$ from the $G a$ subunit. Both the Ga subunit and the $G \beta \gamma$ dimer exert their effects on a wide range of intracellular effectors such as adenylyl cyclase, phospholipase $\mathrm{C}$, ion channels and mitogenactivated protein kinase (ERK) pathway. The Ga subunit has a weak GTPase catalytic activity, thereby slowly hydrolyzing GTP to GDP. The hydrolysis of GTP to GDP on the Ga subunit leads to reassembling of the $G \beta \gamma$ with the $G \alpha$ subunit, terminating signal transduction [22]. RGS proteins rapidly accelerate the termination of $\mathrm{G}$ protein signaling by binding to the Ga subunit and activating its GTPase activity (Figure 1). Therefore, RGS proteins negatively modulate the strength and duration of GPCR-mediated G protein signaling.

Approximately 37 identified proteins belong to the RGS family, which can be further divided into at least 8 subfamilies based on

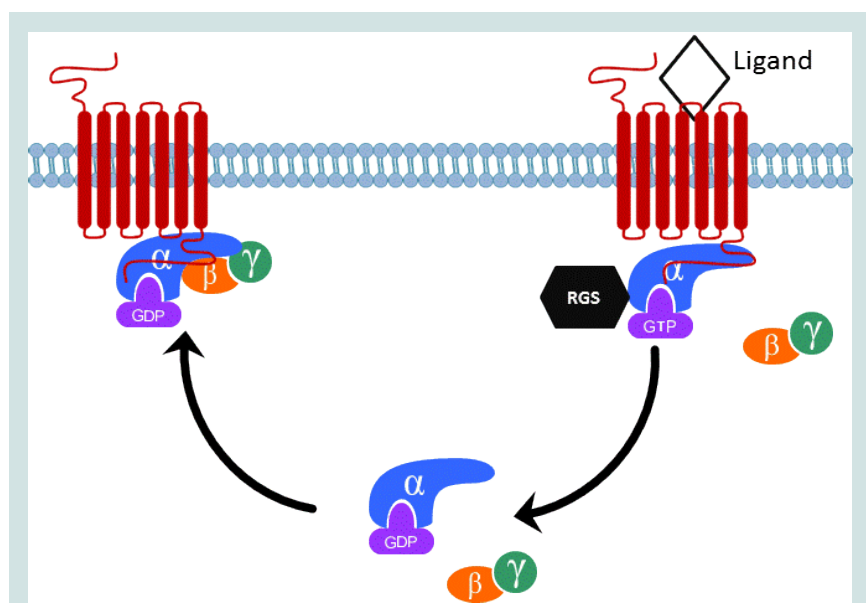

Figure 1: A schematic diagram of the $G$ protein cycle. At the basal state, the Ga subunit is bound to GDP and forms an inactive heterotrimer with GBy subunits. When receptor is activated by agonist, it promotes the exchange of GDP for GTP on the Ga subunit and dissociation of the Ga from the GBy subunits. The $\mathrm{G} \alpha$ and $\mathrm{G} \beta y$ subunits can interact with downstream effectors such as adenylyl cyclase and ion channels to initiate signal transduction. The Ga subunit has the GTPase activity, which slowly hydrolyzes GTP to GDP. RGS proteins directly bind to GTP-bound Ga subunit and enhance its GTPase activity by accelerating the rate of hydrolysis and termination of $G$ protein signaling. The GDP-bound Ga subunit then reassociates with GßY subunits to return to the inactive state. the structure and function similarities [23]. All RGS proteins have a conserved RGS domain containing 125 amino acids, which is the site for binding to the GTP-bound Ga subunit to activate GTP hydrolysis [24]. Although most RGS proteins can act on almost all of the $\mathrm{Ga}$ subunits in the Gai/o and Gq family, different RGS proteins have their own selectivity for $\mathrm{Ga}$ subunits. For example, RGS9 proteins show a bias toward Gao over Gai in the presence of the binding partner G $\beta 5$ whereas RGS7 proteins only regulate Gao signaling as determined by kinetics of GTP hydrolysis in HEK293 cells [25]. Neither RGS9 nor RGS7 proteins exhibit selectivity for Gq in this heterologous expression system. Thus, the RGS domain of RGS proteins is an attractive target for pharmacological manipulation of the GTPase activity of RGS proteins to alter the functionality of associated GPCRs [26]. Moreover, different subtypes of RGS proteins contain a wide range of other signaling domains, which include the $\mathrm{N}$-terminal cysteine string, the $\mathrm{N}$-terminal amphipathic helix, the G protein $\gamma$-like domain, the pleckstrin homology domain, and the Gai/o-GDP binding motif. These domains may dictate the subcellular localization of RGS proteins and/or confer selectivity for receptors or intracellular signaling cascades. For example, the N-terminal cysteine residue and amphipathic helix domain of RGS4 proteins modulate RGS4 membrane localization, intracellular trafficking and functionality [27].

RGS proteins have a unique anatomic and cellular expression pattern. The distribution of RGS proteins in the brain is based primarily on the mRNA expression determined by in situ hybridization due to the lack of specific antibodies for each subtype. Each RGS has a distinct brain region-dependent expression pattern [28]. Here are a few examples of RGS proteins that are present in the mesolimbic dopamine pathway where dopamine D2 receptors are abundantly expressed. RGS2 is predominant in the rat cortex and the striatum $[29,30]$ and is also notable in the dopamine neurons of the VTA [31]. RGS4 is enriched in the rat striatum and hypothalamus [28]. RGS9 is exclusively expressed in the mouse striatum, and co-localizes with D2 receptors [32,33]. RGS19 is present in the rat VTA and NAc and co-localizes with D2 receptors in these regions [34]. The distribution of RGS proteins is also cell-type specific. For instance, RGS2 and RGS4 are equally distributed in the GABAergic neurons of the rat midbrain; however, RGS2 is more notable in the rat midbrain dopaminergic neurons than RGS4 [35]. RGS9 is expressed in D2-containing GABAergic neurons of the mouse striatum $[33,36]$. Because the mRNA expression does not necessarily translate into protein expression, it is warranted in the future to investigate the protein expression pattern of various RGS proteins in the mesolimibic dopamine pathway when antibodies specific for subtypes of RGS proteins become available. The differential distribution of subtypes of RGS proteins further supports the notion that RGS proteins may confer specificity for receptors in a brain-region dependent manner.

A few subtypes of RGS proteins show specificity in modulation of the trafficking and/or functioning of dopamine D2 receptors as demonstrated in heterologous expression systems. For example, overexpression of RGS4, but not RGS2 and RGS9, causes desensitization of D2 receptors measured by quinpirole-induced inhibition of cAMP accumulation in the presence of forskolin in HEK293 cells [11]. However, overexpression of RGS9, but not RGS4, prevents agonist-induced internalization of D2 receptors in HEK293 
cells [12]. This regulation is D2 receptor specific because delta opioid receptors are not affected by the presence of RGS9 protein. Furthermore, RGS19 is recruited by activated D2 receptors to the plasma membrane and attenuates $\mathrm{D} 2$ receptor signaling assessed by quinpirole-induced production of arachidonic acid and quinpiroleinduced inhibition of cAMP accumulation [34]. Although the simplified cell culture systems provide important information on potential interactions between D2 receptors and subtypes of RGS proteins, it remains to be determined whether these interactions occur at the physiological conditions.

\section{RGS mRNA Expression: Modulation by Acute Psychostimulant Administration}

Because RGS proteins are negative modulators of GPCR activity, changes in gene expression profiles are among the most promising sites at which to search for molecular mechanisms that might underlie acute or chronic behavioral responses to psychostimulant treatments. The up- or down-regulation of RGS mRNA levels in responses to acute psychostimulant treatment is to provide more or less RGS proteins to directly or indirectly dampen further activation of dopamine signaling through their interaction with receptors, and may contribute to tolerance or sensitization upon further psychostimulant exposure. Accumulating evidence indicates that RGS mRNA expression is modulated by acute treatment of psychostimulants; however, few studies have examined changes in gene and functionality of receptors and/or G proteins that are potentially associated with targeted RGS proteins in various brain regions. Future research in this direction will provide a better understanding of the modulatory effects of RGS proteins on G-protein mediated GPCR function and signaling.

Changes in RGS gene expression by acute psychostimulant treatment are brain region- and RGS subtype-dependent (See table 1). It has been shown that acute cocaine treatment $(25 \mathrm{mg} / \mathrm{kg}$, i.p.) increases RGS4 mRNA levels in the rat NAc but decreases it in the locus coeruleus (LC) [37]. Dopamine D1/D2 receptors and opioid receptors are abundant in the NAc and LC, respectively; it needs further investigation of whether altered RGS4 mRNA following acute cocaine treatment would lead to changes in the function of D1/D2 and opioid receptors. Moreover, subtypes of RGS proteins show differential responses to acute treatments. For example, acute AMPH $(7.5 \mathrm{mg} / \mathrm{kg}$, i.p. $)$ treatment produces a sustained increase in the rat striatal mRNA levels for RGS3, RGS5 and RGS8 within $4 \mathrm{hrs}$ after the AMPH treatment; however, the treatment causes a time-dependent decrease in RGS9 mRNA levels and has no effect on RGS16 [38]. Additionally, the reported changes in striatal RGS4 mRNA levels following acute AMPH exposure are not consistent varying from a decrease $[39,40]$ to no changes [38]. Likely confounding factors are differences in the animal species, doses of drugs and the time intervals between the drug treatment and sample collection (See table 1).

Although it is unknown how psychostimulants modulate various subtypes of RGS mRNA levels, RGS2 mRNA induction in particular by psychostimulants seems to be dopamine dependent because acute reserpine administration, which rapidly increases synaptic dopamine levels through depletion of dopamine from the vesicles, causes a transient increase in rat striatal RGS2 mRNA levels [41]. This dopamine-dependent induction of RGS2 mRNA is mediated by D1 and D2 receptors [42]. Pretreatment with D1 antagonist
SCH23390 attenuates AMPH-induced increase in RGS2 mRNA levels whereas pretreatment with D2 receptor antagonist raclopride produces an additive effect with AMPH on RGS2 mRNA. It has been further demonstrated that D1 and D2 receptors exert opposing effects on RGS2 mRNA induction. D1 agonist SKF82958 causes an upregulation of RGS2 mRNA levels whereas the D2 agonist quinpirole reduces it $[43,44]$. Interestingly, RGS2 mRNA can also be regulated in a glutamate-dependent manner. Acute treatment with MK-801 or phencyclidine, N-methyl-D-aspartate (NMDA) receptor antagonist, rapidly reduces striatal RGS2 mRNA levels [45]. It has been hypothesized that the cAMP signaling pathway is likely to be involved in modulation of RGS2 mRNA by dopamine or NMDA receptors. Human RGS2 gene contains a cAMP-response element in its promoter region [46]; thus RGS2 expression is affected by drugs that regulate cAMP production. D1 and D2 receptors are known to exert opposite effects on adenylyl cyclase activity and cAMP production, which explains the opposite regulation of RGS2 mRNA expression by these two receptors. Furthermore, blockade of NMDA receptors with MK-801 in rats increases the activity of adenylyl cyclase in striatum [45], which likely attributes to the observed increase in RGS2 mRNA levels following MK-801 treatment.

\section{RGS mRNA Expression: Modulation by Repeated Psychostimulant Administration}

Chronic exposure to psychostimulants induces neuroadaptations which lead to tolerance, sensitization and dependence to psychostimulants. Because RGS proteins are negative modulators of GPCR, an up-regulation of an RGS protein could lead to receptor desensitization whereas a down-regulation could result in receptor sensitization. Thus, changes in RGS mRNA expression following chronic psychostimulant treatment may lead to alterations in the functionality of associated receptors, resulting in persistent dysfunctional dopaminergic systems and thus drug addiction.

Reports on chronic psychostimulant-induced alterations of RGS mRNA levels have been inconsistent (see table 1). One implicating factor is the length of withdrawal from chronic drug exposure. For example, RGS2 mRNA levels in the mouse NAc are increased following 12 days of METH administration $(2 \mathrm{mg} / \mathrm{kg}$, i.p., twice a day) without withdrawal [47]. In contrast, there is no change in striatal RGS2 mRNA levels in mice following 4 days of withdrawal from 7 days of METH administration (10 mg/kg, i.p.) [48]. These data suggest that METH-induced changes in RGS2 mRNA may be transient in mice. Additionally, there is no change in rat striatal RGS4 mRNA levels following 28 days of withdrawal from repeated AMPH administration (1-5 mg/kg, i.p., every other day for 15 injections) [49], which is in contrast to a decrease in striatal RGS4 mRNA expression in rats that had 21 days of withdrawal from 5 days of AMPH treatment (5 mg/kg, i.p.) [50]. Thus, changes in RGS4 mRNA by AMPH treatment seem to be short-lived as well. Because addiction is a chronic disorder and relapse often occurs after a long period of abstinence, it is imperative to study the enduring neuroplasticity in the brain that subserves addiction. Future studies on gene expression of other subtypes of RGS proteins following chronic psychostimulant exposure may provide potential targets for pharmacological intervention of dopamine transmission and thus drug addiction.

The second confounding factor that contributes to inconsistent 
Citation: Chen R, Hemby SE. Dysregulation of RGS Proteins by Psychostimulants. J Addiction Prevention. 2014;2(1): 7.

ISSN: $2330-2178$

Table 1: The gene and protein expression profile of RGS proteins following acute and chronic exposure to psychostimulants.

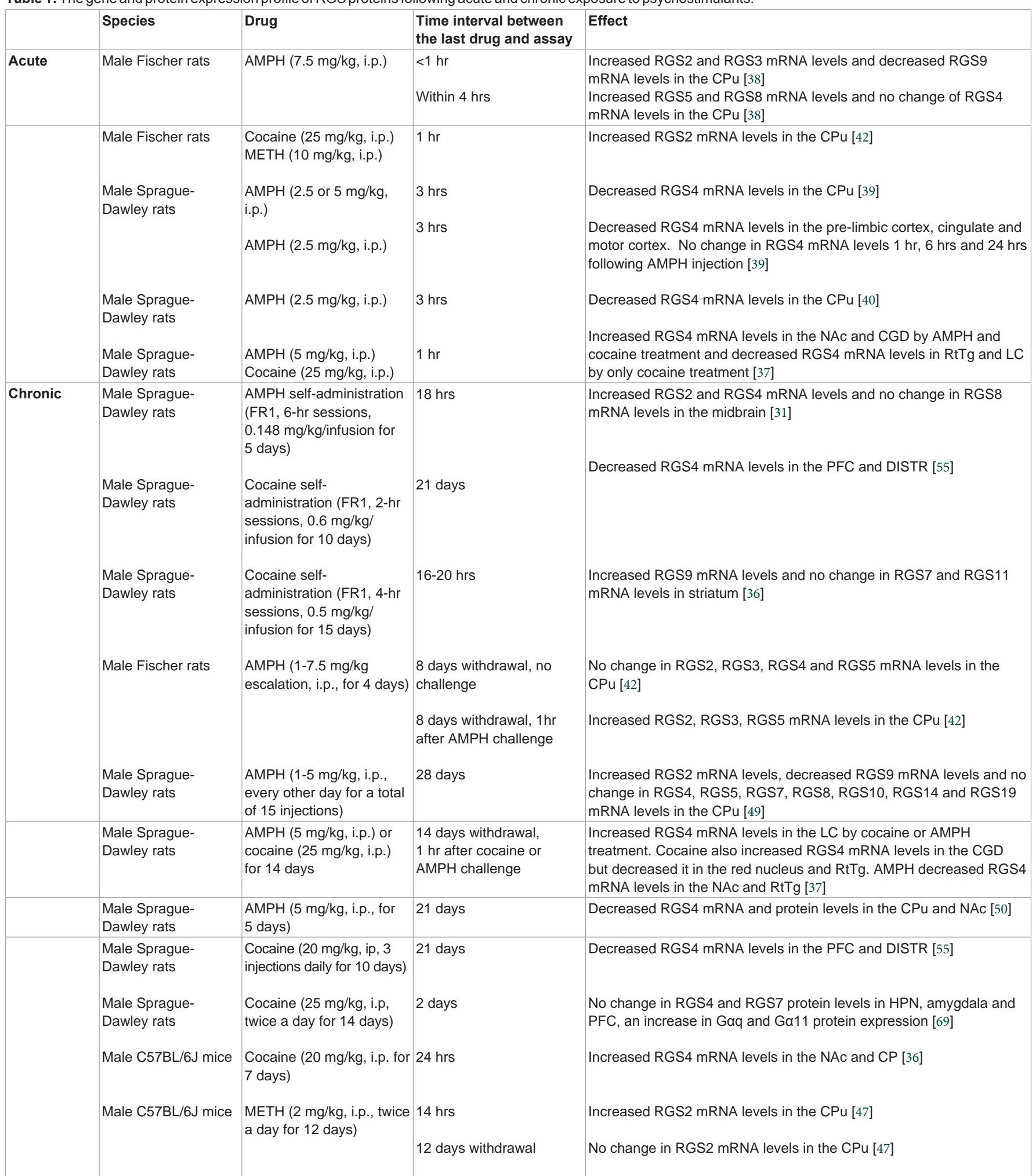

Note: FR1, fixed ratio 1 reinforcement schedule; AMPH, amphetamine; METH, methamphetamine; CPu, caudate putament; VTA, ventral tegmental area; NAc, nucleus accumbens; PFC, prefrontal cortex; DISTR, dorsolateral striatum; CGD, dorsal central grey; RtTg, reticulotegmental pontine nucleus; LC, locus coeruleus; HPN, hypothalamic paraventricular nucleus

reports on RGS gene expression is the route of chronic drug treatment. There is a wealth of data indicating that non-contingent and contingent treatment produce differential profiles in behavioral reinforcement
[51], gene and protein expression [52], and neurochemical responses $[53,54]$. Given the limited data on alterations of RGS mRNA levels produced by self-administration of psychostimulants (See table 
1), it is difficult to draw a clear conclusion on whether contingent and non-contingent treatment of psychostimulants will result in differential RGS gene expression profiles. However, it seems that RGS4 mRNA levels are reduced following non-contingent and contingent cocaine treatment [55]. Cocaine self-administration $(0.6$ $\mathrm{mg} / \mathrm{kg} /$ infusion, 2-hr sessions for 10 days) causes a decrease in rat striatal RGS4 mRNA levels after 21 days of withdrawal, which is in agreement with reduced striatal RGS4 mRNA expression in rats who underwent abstinence for 21 days from chronic treatment of cocaine $(20 \mathrm{mg} / \mathrm{kg}$, i.p., 3 injections per day for 10 days). A lot of work is still needed to determine the gene expression profiles of other subtypes of RGS proteins following chronic contingent and non-contingent psychostimulant treatment.

Finally, it would be interesting to compare the profiles of RGS gene expression following acute and chronic psychostimulant treatment. Alterations in RGS mRNA levels by acute and chronic treatment will elucidate the temporal changes during the addiction process, providing potential molecular mechanisms of receptor desensitization and sensitization that are associated with drug tolerance and sensitization, respectively. Given the current limited data on RGS mRNA expression following acute and chronic treatment of psychostimulants, it is also difficult to draw the conclusion at this moment. Future research should include designs to study timedependent changes in RGS mRNA expression following the same length of withdrawal from acute and chronic treatment to address this question.

\section{RGS Protein Functionality: Modulation of Psychostimulant Responses}

Due to the lack of specific antibodies and inhibitors for many subtypes of RGS proteins, our knowledge of the functional roles of RGS proteins in modulation of dopamine transmission and drug addiction is largely unknown but with a few exceptions such as RGS4 and RGS9 proteins. The availability of RGS protein knockout mice and lentiviral gene delivery approaches to manipulate mRNA and protein expression in vivo provide feasible means to investigate functionality of subtypes of RGS proteins in drug addiction.

RGS4 protein appears to be involved in mediating the effects of AMPH. Abstinence (21 days) following repeated AMPH administration ( $5 \mathrm{mg} / \mathrm{kg}$, i.p. for 5 days) results in behavioral sensitization and a reduction in RGS4 mRNA and protein levels in rat dorsal and ventral striatum [50]. Therefore, an increase in striatal RGS4 protein may dampen AMPH sensitization behavior and $\mathrm{AMPH}$-induced signal transduction. As a matter of fact, it has been shown that lentiviral RGS4 overexpression in the dorsal striatum suppresses acute AMPH-induced locomotor stimulation and attenuates AMPH-induced phosphor-ERK level [56]. RGS4 may modulate AMPH effects through interaction with glutamate receptor 5 (mGluR5) because the blockade of AMPH effects by overexpression of RGS4 in the striatum parallels to the effect produced by mGluR5 antagonist [56]. RGS4 forms a complex with mGluR5 and mGluR5 associated proteins Gaq/11 and phospholipase C- $\beta 1$ (PLC $\beta 1)$ in the striatum as demonstrated by immunoprecipitation [50]. Although repeated AMPH treatment does not alter the total mGluR5 protein expression, the levels of Gaq/11 and PLC $\beta 1$ proteins are increased along with reduced RGS4 proteins [50]. These data suggest that repeated AMPH treatment may enhance the coupling efficiency between $\mathrm{mGluR} 5$ and $\mathrm{G}$ proteins to increase $\mathrm{mGluR} 5$ function, which may partially contribute to AMPH-induced behavioral sensitization. It is important to note that RGS4 can also regulate D2 or D3 receptor function and signaling through a direct interaction as shown in heterologous expression systems [11]. Given the abundant presence of D2/D3 receptors and RGS4 proteins in the striatum, it remains to be determined whether RGS4 proteins are capable of modulating dopamine signaling through D2/D3 receptors in vivo and affect D2 receptor-associated drug-taking and seeking behavior.

RGS9 proteins have been shown to mediate dopamine-related motor and psychostimulant reward behavior. Reduced striatal RGS9 protein levels were observed in animal models of Parkinson's disease [57]. RGS9 knockout mice exhibit dopamine-associated motor deficits such as decreased motor coordination and abnormal involuntary movements by D2 receptor activation [33,58]. Importantly, RGS9 proteins are also involved in psychostimulant action. It has been demonstrated that the level of striatal RGS9 proteins is reduced in rats following withdrawal from the repeated AMPH administration, which parallels D2 receptor hypersensitivity to agonist treatment [49]. Thus, reduced RGS9 protein levels may precipitate addiction-associated behavior. In agreement with this notion, lentiviral overexpression of RGS9 proteins in the NAc reduces locomotor responses to acute and chronic cocaine or AMPH treatment [36]. Although overexpression of RGS9 proteins does not change D2 receptor membrane expression, it attenuates D2 receptor ability to activate G-protein-coupled inwardly rectifying potassium (GIRK). Furthermore, RGS9 overexpression also results in a decrease in locomotor activity stimulated by D2 receptor agonists but not D1 receptor agonists. Conversely, RGS9 knockout mice exhibit hyperactivity to acute cocaine stimulation and augmented reward to repeated cocaine treatment measured by conditioned place preference [36]. These data suggest that RGS9 proteins have specificity for regulation of dopamine transmission by interacting with striatal D2 receptors.

RGS proteins can also indirectly regulate dopamine transmission through other targets such as GIRK channels (see review in [59]). RGS proteins accelerate both activation and deactivation kinetics of GIRK [60]. Because the opening of GIRK channels reduces the firing rates of neurons, changes in RGS proteins in the mesolimbic pathway by psychostimulants would impact dopamine neuron excitability and dopamine release. Furthermore, recent data indicate that RGS2 protein specifically modulates the coupling efficiency between $\gamma$-aminobutyric acid type $B\left(G_{A B A}\right)$ receptors and somatodendritic GIRK3 channels in dopamine neurons of the VTA [35]. Genetic deletion of RGS2 leads to a higher $\mathrm{GABA}_{\mathrm{B}}$-GIRK coupling efficiency, which was demonstrated by an enhanced sensitivity to baclofeninduced GIRK current in RGS2 knockout mice compared to wildtype controls. In addition to RGS2 involvement in GIRK regulation, other RGS proteins such as RGS4 [61], RGS6 [62], RGS7 [63], RGS8 [64] and RGS9 [36] have been shown to modulate the GPCR-GIRK interaction in heterologous expression systems and rodent brain slices as well. Future research should focus on understanding whether these interactions occur in vivo and what the physiological functions of these interactions are.

\section{RGS Proteins as Potential Targets for Drug Abuse}

A growing body of literature indicates that dopamine-related RGS proteins are subjected to modulation by psychostimulants and may be 
potential targets for treatment of drug addiction. As described above, most RGS proteins display brain region-specific distribution and are coupled to specific $\mathrm{G} \alpha$ subunit to modulate receptor-dependent signaling. Thus, small molecules that target the RGS domain of RGS proteins to interfere with the GTPase activity may be able to restore the function of dopamine receptors downregulated or desensitized by psychostimulants. There are some identified small molecule inhibitors of RGS proteins that show promises in subtype selectivity and potency in altering RGS activity, and are being evaluated in vivo $[65,66]$. Furthermore, there are a few reported small-molecule RGS inhibitors that are capable of altering $G$ protein signaling by disrupting the Ga-RGS interaction through an allosteric modulation $[67,68]$. The availability of RGS protein inhibitors will not only provide utility for studying the in vivo function of RGS proteins but also provide a potential means for pharmacological intervention of psychostimulant addiction

\section{References}

1. National Drug Control strategy, Data Supplement 2013.Executive office of the present of the united states.

2. Volkow ND, Fowler JS, Wolf AP, Schlyer D, Shiue CY, et al. (1990) Effects of chronic cocaine abuse on postsynaptic dopamine receptors. Am J Psychiatry 147: 719-724.

3. Nader MA, Morgan D, Gage HD, Nader SH, Calhoun TL, et al. (2006) PET imaging of dopamine $\mathrm{D} 2$ receptors during chronic cocaine self-administration in monkeys. Nat Neurosci 9: 1050-1056.

4. Tsukada H, Kreuter J, Maggos CE, Unterwald EM, Kakiuchi T, et al (1996) Effects of binge pattern cocaine administration on dopamine D1 and $\mathrm{D} 2$ receptors in the rat brain: an in vivo study using positron emission tomography. J Neurosci 16: 7670-7677.

5. Maggos CE, Tsukada H, Kakiuchi T, Nishiyama S, Myers JE, et al. (1998) Sustained withdrawal allows normalization of in vivo [11C]N-methylspiperone dopamine D2 receptor binding after chronic binge cocaine: a positron emission tomography study in rats. Neuropsychopharmacology 19: 146-153.

6. Volkow ND, Wang GJ, Fowler JS, Logan J, Gatley SJ, et al. (1999) Prediction of reinforcing responses to psychostimulants in humans by brain dopamine D2 receptor levels. Am J Psychiatry 156: 1440-1443.

7. Martinez D, Broft A, Foltin RW, Slifstein M, Hwang DR, et al. (2004) Cocaine dependence and $\mathrm{d} 2$ receptor availability in the functional subdivisions of the striatum: relationship with cocaine-seeking behavior Neuropsychopharmacology 29: 1190-1202.

8. Shumay E, Fowler JS, Wang GJ, Logan J, Alia-Klein N, et al. (2012) Repeat variation in the human PER2 gene as a new genetic marker associated with cocaine addiction and brain dopamine D2 receptor availability. Trans Psychiatry 2: e86.

9. Buckholtz JW, Treadway MT, Cowan RL, Woodward ND, Li R, et al. (2010) Dopaminergic network differences in human impulsivity. Science 329: 532.

10. Beaulieu JM, Gainetdinov RR (2011) The physiology, signaling, and pharmacology of dopamine receptors. Pharmacol Rev 63: 182-217.

11. Min C, Cheong SY, Cheong SJ, Kim M, Cho DI, et al. (2012) RGS4 exerts inhibitory activities on the signaling of dopamine D2 receptor and D3 receptor through the N-terminal region. Pharmacol Res 65: 213-220.

12. Celver J, Sharma M, Kovoor A (2010) RGS9-2 mediates specific inhibition of agonist-induced internalization of D2-dopamine receptors. J Neurochem 114 739-749.

13. Hooks SB, Martemyanov K, Zachariou V (2008) A role of RGS proteins in drug addiction. Biochem Pharmacol 75: 76-84.

14. Le Foll B, Gallo A, Le Strat Y, Lu L, Gorwood P (2009) Genetics of dopamine receptors and drug addiction: a comprehensive review. Behav Pharmacol 20: $1-17$.
15. Caine SB, Koob GF (1994) Effects of dopamine D-1 and D-2 antagonists on cocaine self-administration under different schedules of reinforcement in the rat. J Pharmacol Exp Ther 270: 209-218.

16. Barrett AC, Miller JR, Dohrmann JM, Caine SB (2004) Effects of dopamine indirect agonists and selective D1-like and D2-like agonists and antagonists on cocaine self-administration and food maintained responding in rats. Neuropharmacology 47 Suppl 1: 256-273.

17. Caine SB, Thomsen M, Gabriel KI, Berkowitz JS, Gold LH, et al. (2007) Lack of self-administration of cocaine in dopamine D1 receptor knock-out mice. J Neurosci 27: 13140-13150.

18. Self DW, Barnhart WJ, Lehman DA, Nestler EJ (1996) Opposite modulation of cocaine-seeking behavior by D1- and D2-like dopamine receptor agonists. Science 271: 1586-1589.

19. Brunetti M, Di Tizio L, Dezi S, Pozzi G, Grandinetti P, et al. (2012) Aripiprazole alcohol and substance abuse: a review. Eur Rev Med Pharmacol Sci 16: 1346-1354

20. Loebl T, Angarita GA, Pachas GN, Huang KL, Lee SH, et al. (2008) A randomized, double-blind, placebo-controlled trial of long-acting risperidone in cocaine-dependent men. J Clin Psychiatry 69: 480-486.

21. Shorter D, Kosten TR (2011) Novel pharmacotherapeutic treatments for cocaine addiction. BMC Med 9: 119.

22. Hamm HE (1998) The many faces of G protein signaling. J Biol Chem 273: 669-672.

23. Willars GB (2006) Mammalian RGS proteins: multifunctional regulators of cellular signalling. Semin cell Dev Biol 17: 363-376.

24. Berman DM, Gilman AG (1998) Mammalian RGS proteins: barbarians at the gate. J Biol Chem 273: 1269-1272

25. Masuho I, Xie K, Martemyanov KA (2013) Macromolecular composition dictates receptor and $\mathrm{G}$ protein selectivity of regulator of $\mathrm{G}$ protein signaling (RGS) 7 and 9-2 protein complexes in living cells. J Biol Chem 288: 2512925142

26. Kimple AJ, Bosch DE, Giguere PM, Siderovski DP (2011) Regulators of G-protein signaling and their Galpha substrates: promises and challenges in their use as drug discovery targets. Pharmacol Rev 63: 728-749.

27. Bastin G, Singh K, Dissanayake K, Mighiu AS, Nurmohamed A, et al. (2012) Amino-terminal cysteine residues differentially influence RGS4 protein plasma membrane targeting, intracellular trafficking, and function. $\mathrm{J}$ Biol Chem 287: 28966-28974.

28. Gold SJ, Ni YG, Dohlman HG, Nestler EJ (1997) Regulators of G-protein signaling (RGS) proteins: region-specific expression of nine subtypes in rat brain. J Neurosci 17: 8024-8037.

29. Taymans JM, Wintmolders $C$, Te Riele $P$, Jurzak M, Groenewegen HJ, et al (2002) Detailed localization of regulator of $G$ protein signaling 2 messenger ribonucleic acid and protein in the rat brain. Neuroscience 114: 39-53.

30. Grafstein-Dunn E, Young KH, Cockett MI, Khawaja XZ (2001) Regiona distribution of regulators of G-protein signaling (RGS) 1, 2, 13, 14, 16, and GAIP messenger ribonucleic acids by in situ hybridization in rat brain. Brain Res Mol Brain Res 88: 113-123.

31. Calipari ES, Sun H, Eldeeb K, Luessen DJ, Feng X, et al. (2014) Amphetamine Self-Administration Attenuates Dopamine D2 Autoreceptor Function. Neuropsychopharmacology : official publication of the American College of Neuropsychopharmacology.

32. Mancuso JJ, Qian Y, Long C, Wu GY, Wensel TG (2010) Distribution of RGS9-2 in neurons of the mouse striatum. J Neurochem 112: 651-661.

33. Kovoor A, Seyffarth P, Ebert J, Barghshoon S, Chen CK, et al. (2005) D2 dopamine receptors colocalize regulator of G-protein signaling 9-2 (RGS9-2) via the RGS9 DEP domain, and RGS9 knock-out mice develop dyskinesias associated with dopamine pathways. J Neurosci 25: 2157-2165

34. Jeanneteau F, Guillin O, Diaz J, Griffon N, Sokoloff P (2004) GIPC recruits GAIP (RGS19) to attenuate dopamine D2 receptor signaling. Mol Biol Cell 15: 4926-4937. 
35. Labouebe G, Lomazzi M, Cruz HG, Creton C, Lujan R, et al. (2007) RGS2 modulates coupling between GABAB receptors and GIRK channels in dopamine neurons of the ventral tegmental area. Nat Neurosci 10: 15591568.

36. Rahman Z, Schwarz J, Gold SJ, Zachariou V, Wein MN, et al. (2003) RGS9 modulates dopamine signaling in the basal ganglia. Neuron 38: 941-952.

37. Bishop GB, Cullinan WE, Curran E, Gutstein HB (2002) Abused drugs modulate RGS4 mRNA levels in rat brain: comparison between acute drug treatment and a drug challenge after chronic treatment. Neurobiol Dis 10 334-343.

38. Burchett SA, Volk ML, Bannon MJ, Granneman JG (1998) Regulators of $G$ protein signaling: rapid changes in mRNA abundance in response to amphetamine. J Neurochem 70: 2216-2219.

39. Schwendt M, Gold SJ, McGinty JF (2006) Acute amphetamine downregulates RGS4 mRNA and protein expression in rat forebrain: distinct roles of D1 and D2 dopamine receptors. J Neurochem 96: 1606-1615.

40. Gonzalez-Nicolini V, McGinty JF (2002) Gene expression profile from the striatum of amphetamine-treated rats: a cDNA array and in situ hybridization histochemical study. Brain Res Gene Expr Patterns 1: 193-198.

41. Geurts M, Maloteaux JM, Hermans E (2003) Altered expression of regulators of G-protein signaling (RGS) mRNAs in the striatum of rats undergoing dopamine depletion. Biochem Pharmacol 66: 1163-1170.

42. Burchett SA, Bannon MJ, Granneman JG (1999) RGS mRNA expression in rat striatum: modulation by dopamine receptors and effects of repeated amphetamine administration. J Neurochem 72: 1529-1533.

43. Taymans JM, Leysen JE, Langlois X (2003) Striatal gene expression of RGS2 and RGS4 is specifically mediated by dopamine D1 and D2 receptors: clues for RGS2 and RGS4 functions. J Neurochem 84: 1118-1127.

44. Taymans JM, Kia HK, Claes R, Cruz C, Leysen J, et al. (2004) Dopamine receptor-mediated regulation of RGS2 and RGS4 mRNA differentially depends on ascending dopamine projections and time. Eur J Neurosci 19 2249-2260.

45. Taymans JM, Cruz C, Lesage A, Leysen JE, Langlois X (2005) MK-801 alters RGS2 levels and adenylyl cyclase sensitivity in the rat striatum. Neuroreport 16: $159-162$

46. Siderovski DP, Heximer SP, Forsdyke DR (1994) A human gene encoding a putative basic helix-loop-helix phosphoprotein whose mRNA increases rapidly in cycloheximide-treated blood mononuclear cells. DNA Cell Biol 13 125-147.

47. Piechota M, Korostynski M, Sikora M, Golda S, Dzbek J, et al. (2012) Common transcriptional effects in the mouse striatum following chronic treatment with heroin and methamphetamine. Genes Brain Behav 11: 404-414

48. Park SW, Shen X, Tien LT, Roman R, Ma T (2011) Methamphetamineinduced changes in the striatal dopamine pathway in mu-opioid receptor knockout mice. J Biomed Sci 18: 83.

49. Seeman P, Ko F, Jack E, Greenstein R, Dean B (2007) Consistent with dopamine supersensitivity, RGS9 expression is diminished in the amphetamine-treated animal model of schizophrenia and in postmortem schizophrenia brain. Synapse 61: 303-309.

50. Schwendt M, McGinty JF (2007b) Regulator of G-protein signaling 4 interacts with metabotropic glutamate receptor subtype 5 in rat striatum: relevance to amphetamine behavioral sensitization. J Pharmacol Exp Ther 323: 650-657.

51. Markou A, Arroyo M, Everitt BJ (1999) Effects of contingent and noncontingent cocaine on drug-seeking behavior measured using a secondorder schedule of cocaine reinforcement in rats. Neuropsychopharmacology 20: $542-555$

52. Jacobs EH, Smit AB, de Vries TJ, Schoffelmeer AN (2003) Neuroadaptive effects of active versus passive drug administration in addiction research. Trends Pharmacol Sci 24: 566-573.

53. Hemby SE, Co C, Koves TR, Smith JE, Dworkin SI (1997) Differences in extracellular dopamine concentrations in the nucleus accumbens during response-dependent and response-independent cocaine administration in the rat. Psychopharmacology 133: 7-16.

54. Fumagalli F, Moro F, Caffino L, Orru A, Cassina C, et al. (2013) Regionspecific effects on BDNF expression after contingent or non-contingent cocaine i.v. self-administration in rats. Int J Neuropsychopharmacol 16: 913918.

55. Schwendt M, Hearing MC, See RE, McGinty JF (2007a) Chronic cocaine reduces RGS4 mRNA in rat prefrontal cortex and dorsal striatum. Neuroreport 18: $1261-1265$

56. Schwendt M, Sigmon SA, McGinty JF (2012) RGS4 overexpression in the rat dorsal striatum modulates mGluR5- and amphetamine-mediated behavior and signaling. Psychopharmacology (Berl) 221: 621-635.

57. Yin LL, Cao Y, Xie KQ (2010) Decreased RGS9 protein level in the striatum of rodents undergoing MPTP or 6-OHDA neurotoxicity. Neurosci Lett 479: 231-235.

58. Blundell J, Hoang CV, Potts B, Gold SJ, Powell CM (2008) Motor coordination deficits in mice lacking RGS9. Brain Res 1190: 78-85.

59. Lomazzi M, Slesinger PA, Luscher C (2008) Addictive drugs modulate GIRKchannel signaling by regulating RGS proteins. Trends Pharmacol Sci 29: 544549 .

60. Doupnik CA, Davidson N, Lester HA, Kofuji P (1997) RGS proteins reconstitute the rapid gating kinetics of gbetagamma-activated inwardly rectifying K+ channels. Proc Natl Acad Sci U S A 94: 10461-10466.

61. Chuang HH, Chuang AY (2012) RGS proteins maintain robustness of GPCRGIRK coupling by selective stimulation of the $G$ protein subunit Galphao. Sci Signal 5: ra15.

62. Maity B, Stewart A, Yang J, Loo L, Sheff D, et al. (2012) Regulator of G protein signaling 6 (RGS6) protein ensures coordination of motor movement by modulating GABAB receptor signaling. J Biol Chem 287: 4972-4981.

63. Keren-Raifman T, Bera AK, Zveig D, Peleg S, Witherow DS, et al. (2001) Expression levels of RGS7 and RGS4 proteins determine the mode of regulation of the $\mathrm{G}$ protein-activated $\mathrm{K}(+)$ channel and control regulation of RGS7 by $\mathrm{G}$ beta 5. FEBS Lett 492: 20-28.

64. Jeong SW, Ikeda SR (2001) Differential regulation of G protein-gated inwardly rectifying $\mathrm{K}(+)$ channel kinetics by distinct domains of RGS8. J Physiol 535: 335-347.

65. Turner EM, Blazer LL, Neubig RR, Husbands SM (2012) Small Molecule Inhibitors of Regulator of $G$ Protein Signalling (RGS) Proteins. ACS Med Chem Lett 3: 146-150.

66. Blazer LL, Zhang H, Casey EM, Husbands SM, Neubig RR (2011) A nanomolar-potency small molecule inhibitor of regulator of G-protein signaling proteins. Biochemistry 50: 3181-3192.

67. Roman DL, Blazer LL, Monroy CA, Neubig RR (2010) Allosteric inhibition of the regulator of $\mathrm{G}$ protein signaling-Galpha protein-protein interaction by CCG-4986. Mol Pharmacol 78: 360-365.

68. Blazer LL, Roman DL, Chung A, Larsen MJ, Greedy BM, et al. (2010) Reversible, allosteric small-molecule inhibitors of regulator of $G$ protein signaling proteins. Mol Pharmacol 78: 524-533.

69. Carrasco GA, Zhang Y, Damjanoska KJ, D'Souza DN, Garcia F, et al. (2003) A region-specific increase in Galphaq and Galpha11 proteins in brains of rats during cocaine withdrawal. J Pharmacol Exp Ther 307: 1012-1019.

\section{Acknowledgements}

The authors are supported by the National Institute on Drug Abuse grants DA030890 (RC), DA012498 (SEH) and P50 DA006634 (SEH). The authors declare no conflict of interests. 